\title{
The Impact of the Implementation of Monitoring and Evaluation Reforms on the Performance of Public Elementary School Literacy and Arithmetic Education Programs in Nairobi County, Kenya
}

\author{
Stalli Selis Kerimi ${ }^{1}$, Dr. Angalini Subiaa Melwa ${ }^{2}$, Prof. Derothy Ndange Kjalo \\ ${ }^{1}$ P.O. Box 73600 City Square, ODEL Campus, University of Nairobi, Nairobi, 00200, Kenya \\ ${ }^{2}$ P.O. Box 30197 GPO, ODEL Campus, University of Nairobi, Nairobi, 00100, Kenya \\ ${ }^{3}$ Profssor, P.O. Box 30197 GPO, ODEL Campus, University of Nairobi, Nairobi, 00100, Kenya
}

\begin{abstract}
The purpose of this study was to examine the influence of implementing change on performance of literacy and numeracy educational programme. Descriptive survey research design and correlation design were used. A sample of 335 was drawn from a target population of 2053. 281 questionnaires were returned representing a response rate of $84 \%$. Analysis of quantitative data was presented in frequencies and percentage whereas the mean and standard deviation were used to measure central tendency and dispersion respectively. Simple linear regression was conducted to test and measure both the relationship and strength of independent and dependent variable. The results revealed that $r=0.581, R^{2}=0.337$, critical value was 3.875 less than the $F$ value of 142.010 hence the model was fit, and the unstandardized beta coefficient was 0.445 . It is concluded that implementing change influences performance of literacy and numeracy educational programme. The study recommends further research on utilization of project findings.
\end{abstract}

Keywords: Implementing Change, Monitoring and Evaluation, Literacy and Numeracy Educational Programme, performance of projects

\section{Introduction}

Education helps in promoting accession of understanding, skillfulness, and a holistic turn of events to an individual which helps one to acquire good morals and manners. Education is also recognized as single drivers of growth and social evolution aspects. Despite much efforts made by key stakeholders in education, performance is still low and specifically on literacy and numeracy which is the backbone of basic education. Much resources like finances, human services and other materials have been put in place to improve school infrastructure so as to assure that the child has friendly school environment in order to improve in there learning skills. There are educators who exit having been coached on how to instruct learners in schools leaving them at the mercy of those who are no clue of the new methodologies taught by the implementing organization. Even if the students have been able to access schools trend on performance is still low and needs immediate attention (Mulongo 2013).

Quality education needs potential collaborative practices from key education stakeholders in order for any improvement to be experienced and much emphasizes to potential benefits on every individual involved in learning process. International education literature highlights that there are desirability of participation in implementing collaboration-based on processes in the community development which has proved to have very little success in trying to meet the required standards. Also there are combined re-arrangement in teaching fraternity according to constitution of Kenya 2010in trying to meet the global competition in getting quality education that is sustainable for development of holistic individual (Ministry of
Education, 2013). This will help meet the aim of achieving the set goals of making Kenya an industrialization country by 2030. This cannot happen if there are precedents resources transferred to schools which are undertaking primary education programme and with over populated classrooms thus affecting teacher-pupil ratio compromising the achievement of quality education (Piper, Jempkemei and Kibukho, 2015). This can only be a reality if all the stakeholders are involved in the learning systems and implementing changes done in the teaching sector.

Utilization of monitoring and evaluation information for future use is vital in any organization especially in managing projects to deliver some outcomes which will add value to the organization. The way of gathering and collecting this information is more structured form of gauging the performance of projects as posited by (Raymond and Bergeron, 2008). One way of collecting quality data is through well designed instruments which generate the right information needed for capturing monitoring and evaluation data which helps in giving the right report, lesson learnt and making any changes needed in the projects. Management of monitoring and evaluation information needs to be consistent and participatory for it to be sustainable (Fardel and Brown, 2010). The utilization and managing of monitoring and evaluation information is key since helps project leaders, the monitoring and evaluation staff and all the stakeholders involved in the projects in quality decision making. The process of tracking information and making changes in projects where necessary specifically with intervening projects delivering monitoring and evaluation findings to policy makers and curriculum developers. Project intervention is an important aspect required in implementing change for monitoring and evaluation results and giving 
feedback of information collected. Performance of literacy and numeracy educational skills should be seen in learners being able to read, write, speak fluently, be able to recognize alphabetic letters and calculate simple arithmetic calculation with ease. The intervention projects provided enough materials for learning but should consistently monitor and evaluate activities on the ongoing and completed projects for better performance (Karim 2011).

Implementing change for monitoring and evaluation is very critical to most programme and especially numeracy and literacy educational programme. There has been an outcry that most programme do not implement the changes made neither do they transmit the results and review the reports given hence carrying forward the problems highlighted earlier on. Therefore, implementation of this process has been inadequate hence resulting into low performances of learning skills in basic education. Implementation changes has been noted to be an issue for most of the projects according to Nzweke, Olandenjo and Emoh (2015) on evaluation of factors necessary for accomplishing the implementation of project in Anambra state, Nigeria states that factors responsible for project success are numerous but if these factors are not followed well implementing the changes found could be a Mistry. On the other hand, Ouko (2015) emphasized that implementing change for monitoring and evaluation has revealed that pupil's performance improved in numeracy than opposed to literacy.

\section{Statement of the Problem}

Stakeholders start execution on Participatory Monitoring and Evaluation process in evolving an ordinary creativity and coming together on ways of measuring end results and procedures that require monitoring and evaluating programme. The procedure of learning is an experience for participants who are actively working in projects and are willing in making any corrections for better performance in the projects. Much emphasis can be placed on identifying the lessons learned that will assist the participants improve the programme implementation and assess whether targets were achieved (Estrella 2000).

This is a methodical process for coming into being with the results that are applicable on end results, production, operations and pursuits of projects. A number of activities play part in producing output, which led to an outcome, and a number of outcomes influence on the findings. The collisions hackles also incorporate procedures, such as structures, strategies, and methods that are applicable to attain findings, and describe the happening connecting stakeholders as the project is ongoing on the implementation process hence project performance. Having this procedures helps groups and the community to analyze what is workable and what is not workable and give a report of why it is not working. Critical thinking sends back on how members ought to progress in the project in attaining its goals and recaps are necessary.

The utilization and managing of M\&E information is very vital because in helping project leaders, the M\&E staff and key stakeholders participate in projects in quality corrective measures, procedures of tracking information and ways of making changes where need be in the projects. It will also help in resources allocation and consistent monitoring and evaluation activities including having the overall project performance (Karim, 2011).

Implementing change is very critical to most programme and especially numeracy and literacy educational programme. There has been an outcry that most programme do not implement changes made, then the problem continues or becomes even worse. Therefore the implementation of these changes has been inadequate hence resulting into failure to attain objectives of Literacy and Numeracy educational programme. It is on the basis of this background that study establishes how participatory Monitoring and Evaluation process influence the performance of literacy and numeracy educational programme in public primary schools in Nairobi County.

\subsection{Objective of the study}

The objective of the study was to assess how implementing change influence performance of literacy and numeracy educational programme in public primary schools in Nairobi county, Kenya.

\subsection{Hypothesis of the study}

The following hypothesis were tested:

i) $\mathbf{H}_{\mathbf{0}}$ :Implementing change has no significant influence on performance of literacy and numeracy educational programs in public primary schools in Nairobi County, Kenya.

ii) $\mathbf{H}_{1}$ : Implementing change has significant influence on performance of literacy and numeracy educational programs in public primary schools in Nairobi County, Kenya

Implementing change was considered vital in influencing the performance of literacy and numeracy educational programme

\section{Literature Review}

Stakeholder's execution on Participatory Monitoring and Evaluation process is evolving on an ordinary creativity and coming together ways of measuring end results and procedures that require monitoring and evaluation. The procedure of learning is an experience for participants who are actively working in projects and are willing in making any corrections for better performance in the projects. Much emphasis can be placed on identifying the lessons learned that will assist the participants improve the programme implementation and assess whether targets were achieved (Estrella 2000). This is a methodical process for coming into being with the results that are applicable on end results, production, operations and pursuits of projects. A number of activities that play part in producing output, which led to an outcome that influenced the findings. The collisions hackles also incorporate procedures, such as structures, strategies, and methods that are applicable to attaining desired findings. This also describes the happenings which connect stakeholders in an ongoing projects and implementation process hence good project performance. Having this procedures groups in the community analyze what is 
workable and what is not workable and give a report of why it is not working. Critical thinking sends back on how members ought to progress in the project in attaining its goals and recaps are necessary for better yields.

Critical thinking is required in carrying out how result are accessed by every member, activities, procedures and guidelines, were achieved through baseline, midline and end line reports of the piloted projects which were earlier on done indicating the performances achieved and what was not achieved. Research Training International (2015), as well as Njuki, Kaaria, Colletta and Sanginga (2006) emphasized on the same. New ideas brought by the three reports enhanced need to make changes in implementation process. In the process the data collected was reviewed and transmitted to the necessary bodies for future use. Through the data analysis and critical thinking on what has been attained, the details of information collected by the evaluation staff from the implementing groups, calculated costs and profits from production activities were used to check whether any progress had occurred. Measures on participation in group activities were carried out in different group meetings, projects activities and reflections were made on analysis to enable the organization learn from the success or failures of the projects. It could be assumed that different factors hindered facilitation of project performance as suggested by Karemesi (2010), Aremu(2000) and Mayama (2012) and more specifically on education intervention projects.

In Kenya learning of literacy and numeracy skills has become a menace thus making the government of Kenya to advocate that there is need for intervention programme. Tools and materials to cub these menace should be designed as stipulated by Daly (2015) on execution of literacy intercession 'Station Teaching' in baby institutions in Irish primary schools', whereby he cited numerous tactics and methods were vital to facilitate efficiency of educating in languages in nursery centers inclusive of phonology understanding phonetics, complex of new words, eloquence, compacting and scribbling of new words. These tactics are performed in institutions where instruction take place. Early intercessions of starter's learners acquire languages correctly depending on the instructors. The expertise of the teacher is key to improving the literacy attainment of students though numerous and extensive instruction should be embraced in order to equip educators who are the main executors of syllabus and allocation of resources to schools so that programme can be sustained even when the funders are withdrawn. The study has not explained how teachers and administrators implement the necessary and required skills hence need for this study to be carried out.

The intervention projects on learning basic skills, through the funding non-governmental organizations have helped in bring change by use of diagnostic tools as observed by Forster (2009) on Literacy and Numeracy diagnostic tools on evaluation, to produce good results on Literacy and Numeracy education, the Department of Education, Employment and Workplace Relations (DEEWR) have at glace considered methods of designing of Literacy and Numeracy distinctive instruments to apply in Australian institutions. Exploring for possible instruments needs to be applied in Australian schools which differ so much on ideas conceptualization and the intentions to be carried out. This is no different in Kenyan schools which requires correct tolls to be applied and used in order to make changes in primary schools. There is need to help teachers and educators to have a common tool to use in improving the performance of learning process. Instruments used at bottom stages identifying ability comprising framework which describe the stages of attainment in comparison with learner's judgment on report and monitoring. Instructors gather proof of pupils' recognition of sounds and strong points and drawn from conclusions from rear side stage of framework specified, and assigned to different Levels of diagnostic powers.

By use of determined frames of power and assessment methodology, pupil's involvement eases intercession sessions and communication channels to parents. Recognizing ways of impediments in resources allocations and details obtaining education structures must take serious measures in bridging the gaps as identified by (Asikhia 2010). Therefore there is need for this study to assess diversity of instruments in diagnosing authority and purposively getting entry into Literacy and Numeracy understanding, skillfulness and studying of the learners. Also to seek ways on how schools and teachers can be assisted in selecting appropriate apparatus which help in determining different motives and added assets. This facilitates efficiency in identification of information in various institutions and at classroom level to cater for individual learner. A study by (Ercikan, 2009) on the assessment of literacy evaluation and monitoring programme (LAMP) / UNESCO institute for statistics (UIS) also emphasized the point on teacher diagnostic power in assisting the learner to get the right information and be able to conceptualize the ideas.

To overcome issues of teacher-pupil ratio, inadequate resources and insufficient substantial infrastructure according to Mege (2014) focusing on influence of school environmental elements instructing-teaching operations as exhibited in learning institutions which have insufficient substantial infrastructure and inadequate learning resources among many other challenges USAID and other funding bodies have come in to intervene for the government of Kenya. This is experienced in almost all the public primary schools in Kenya as posited by Jempkemei and Kibukho (2015) on the quality of education in learning institutions. The situation in the country on high enrollment class is alarming since the introduction of free primary education(Msungu2015). Numerous institutions have many students per class which most teachers are not comfortable with hence low performance of the literacy and numeracy skills. The government came in by employing more teachers to cub the problem of teacher-pupil ratio as investigated by Abuya, Admassu, Ngware, Onsomu, and Oketch (2015)inthe role of teachers trying to bridge the gap brought about by free primary education.

\subsection{Theoretical Framework}

The study article is anchored on theory of change 


\subsubsection{Theory of Change}

The study was guided by the Theory of change popularized by Carol Weiss in 1995. Theory of change is a central process by which change comes about to an individual, a group and an organization in the community derived from formal research based on theory and understanding of how things work in an institution. Theory of change helps in linking up the project activities to the desired change that a projects is targeting to change (Rogers, 2002). The study article sought to change the perception of stakeholder's involvement in the project cycle and participation in all the stages/ steps of participatory monitoring and evaluation process. In this study the theory of change explains how the monitoring and evaluation are going to be implemented so as to meet the set objectives of the projects which needs to bring changes in learning of literacy and numeracy skills and enhancement of knowledge acquisition.

Theory of change can be developed for an intervention where objectives and activities are identified and tightly planned beforehand. In this research the objectives and activities of the projects are already set at the begging when preparing the monitoring and evaluation plan which helps in identifying the stakeholders, their roles, types of stakeholders, and the in-depth of participation in the planning and implementation of the projects. This allows room for change and adapts any emerging issues and accepting any responses made by partners and other stakeholders focusing mainly efficiency and effectiveness on peace building interventions in any projects. Theory of change therefore is a specific type of methodology for planning, participation, evaluation and monitoring for nonprofit making organizations and the government sectors which need to promote social change.

The variables in the study concur with this theory in that the planning process, conceptualization and operationalization which include a situation analysis in identifying the nature and the extent of the problem or opportunities to be addressed is fully investigated. Valters (2014) noted that Theory of change can define immediate, intermediate, shortterm, long-term and ultimate outcomes and shows the intended outcomes and contributions to addressing the problems. It is a road map that leads to better planning and a detailed way of how activities are linked to one another and how change happens. It helps in measuring progress towards achievements of long-term goals even beyond the identification of programme outputs, reviewing collected data, number of transmitted reports, utilization of monitoring and evaluation results and project intervention. For the project intervention Morrell, Young, Navarrete, Omarsh and van Egmond (2014) found out that there were improvement on literacy level and attendance of learners in marginalized schools and the girls changed their attitude and their character upon the intervention programme.

Butt, Naaranoja and Savolainen (2005) recognized the value and importance of evaluation in respect to theory of change by way of stakeholder participation and knowledge management whereby they stated that, "effective communication ensures stakeholder participation in the change management process through teamwork and empowerment". Similarly, Blake and Ottoson (2009) also agreed together there are elements that shape the parameters of knowledge utilization and they noted three aspect namely, what counts as knowledge, use of knowledge and meaning of multiple knowledge utilization. The relationship of this theory and the current study is that it helps in identifying the problem under investigation and tries to look for solutions, planning and making decisions on the projects objectives. The opinion of the researcher is that, theory of change is completely in line with the study under investigation, since it is investigating on how change can occur in learning projects and especially the reading skills and simple arithmetic skills

\subsection{Conceptual Framework}

The conceptual framework adopted in this study presents the relationship between the independent and dependent variables. Thus, the independent variable is implementing change for $M \& E$ whereas the dependent variable refers to performance of literacy and numeracy educational programme. Figure 1 is a detailed illustration of this relationship.
Independent variable

Implementing change for monitoring and evaluation
Implementing change for $\mathrm{M} \& \mathrm{E}$

- Reviewing collected data

- Number of transmitted reports

- Utilization of M\&E results

- Project intervention

\section{Dependent Variable}

Performance of Literacy and Numeracy Educational
Programme
- Reading skills
- Simple arithmetic calculations skills
- Letter recognition
- Beneficiary Satisfaction
- Proficiency skills in listening of literacy and
- numeracy skills
- numericiency skills in speaking of literacy and
- $\quad$ proficiency skills and writing
- Transition rate improved
- Class average performance improved

Figure 1: Conceptual Framework of Influence of Implementing Change for Monitoring and Evaluation on Performance of Literacy and Numeracy Educational Programme 


\section{Research Methodology}

The study article used pragmatism paradigm which is noncommittal structure of philosophy in real life. In this regard pragmatism tends to apply mixed methods research which provides a more comprehensive approaches for collecting and analyzing data rather than using only one way of either qualitative or quantitative (Creswell and Plano, 2011). According to Migiro and Magangi (2011) states that mixed methods research encourages researchers to use multiple approaches to collecting and analyzing data within a single study, recognizing the limitations of using a single method. In this study, quantitative data was collected using structured questionnaires whilst qualitative data was collected using interview schedules.

The study adapted descriptive research survey design and correlational research design. According to Cooper and Schindler (2003), a descriptive survey research design study is concerned with finding out the what, where and how of a phenomenon. Correlational research design was to help in getting the direction and strength of the relationships between stakeholder engagement and performance of literacy and numeracy of education progamme.

The unit of analysis were ongoing and completed literacy and numeracy educational programme, while the unit of inquiry included Head Teachers, Lower Primary School Teachers, the Curriculum Support Officers and officers Research Triangle International Institutes.

A sample size of 335 respondents was arrived using Yamen formula of 1967 from a target population of 2053, while data was collected from the respondents through questionnaires and interview schedules. Purposive sampling was employed to 33 Head Teachers, 3 curriculum support officers and 5 Research Triangle International Institutes officers who had an in-depth information pertaining to study constructs, while 294 lower public primary school teachers were selected through simple random sampling from 1800 teachers.

Data collected was both qualitative and quantitative data which was first cross checked for correctness, coded and analyzed according to thematic areas. Quantitative data was analyzed through employing descriptive and inferential statistics generated thus the descriptive results were presented in tabular forms using, frequencies, arithmetic means and standard deviation while inferential statistics were obtained using Pearson's Product Moment correlation while F-test was used to test hypotheses.

Both qualitative and quantitative data explained the influence of stakeholder engagement and performance of literacy and numeracy educational programme exhaustively. After collection activity, the researcher edited, coded categorized, checked all the blank responses and keyed in the information into SPSS program version 25 for actual analysis to be carried out. The data was subjected to Normality test which was done through checking and found to follow normal distribution.

Pearson's Product Moment correlation coefficient(r) was used to describe the strength of relationship between the independent predictor variable and dependent variable. The test was carried out on a two-tail test since it allowed for either influence to the positive or negative direction while hypothesis testing was tested at $95 \%$ level of confidence and significance level of .0 .05 . The hypothesis with linear relationship was analyzed using simple regression analysis and Pearson's Product Moment Correlation used for interpretation of results. Together with simple graphics analysis, descriptive statistics form the basis of virtually every quantitative analysis to data. Correlation analysis to establish the relationship between the independent and dependent variables was employed.

Interpretation of the results for the linear relationships of this study was based on; for a weak correlation $r$ ranging from +0.10 to +0.29 ; moderate correlation between +0.30 to +0.49 ; while strong correlation from +0.50 to +1.0 (Shirley, Stanley, and Daniel,2005). Hence, $r=0.581$ implies a positive strong relationship between implementing change and performance of literacy and numeracy educational programme.

\section{Findings and Discussions}

The main goal of the study was to assess how implementing change influence performance of literacy and numeracy educational programme in public primary schools in Nairobi county, Kenya. Questionnaires given to respondents were 335 and 281 were filled and returned back while 54 were not returned. This represented a return rate of $84 \%$ which is generally representative enough for analysis of results of the target population. Babbie, (2003) posits that $70 \%$ and above is deemed to be adequate enough for any study. For this study it was within the rage of stipulated percentage of $84 \%$ above the agreed one making it possible for the study to proceed.

\subsection{Overall Descriptive Analysis on Implementation Change}

Performance of literacy and numeracy educational programme has a notable contribution towards economic growth and poverty eradication. In order to establish the magnitude to which literacy and numeracy project performance was influenced by reading skills, simple arithmetic calculations, letter recognition, beneficiaries satisfaction, proficiency skills in listening of literacy and numeracy skills, proficiency skills in speaking of literacy and numeracy skills, proficiency skills in writing skills, timely Acquisition of literacy and numeracy skills, transitional rate improved, class average performance improved upon the intervention of the educational programme in this study, a thorough investigation was done on these variables. The respondents were subjected to several questions related to the variables under study in a likert scale of 1-5 whereby; Strongly disagree(SD)=1, $\operatorname{Disagree}(\mathrm{D})=2, \operatorname{Neutral}(\mathrm{N})=3, \operatorname{Agree}(\mathrm{A})=4$ and Strongly $\operatorname{Agree}(\mathrm{SA})=5$. Line mean score and standard deviation of each of the opinions was compared with the respective composite scores for interpretation. The results are presented in Table 1. 
Table 1: Performance of Literacy and Numeracy Educational Programme

\begin{tabular}{|c|c|c|c|c|c|c|c|}
\hline Performance of literacy and numeracy educational programme statements & $\begin{array}{c}\mathrm{SD} \\
\mathrm{F} \\
(\%)\end{array}$ & $\begin{array}{c}\mathrm{D} \\
\mathrm{F} \\
(\%)\end{array}$ & $\begin{array}{c}\mathrm{N} \\
\mathrm{F} \\
(\%)\end{array}$ & $\begin{array}{c}\mathrm{A} \\
\mathrm{F} \\
(\%)\end{array}$ & $\begin{array}{c}\text { SA } \\
\text { F } \\
(\%)\end{array}$ & Mean & $\begin{array}{c}\text { Std. } \\
\text { Deviation }\end{array}$ \\
\hline $\begin{array}{l}\text { 1.There is improvement in reading learning skills of the pupils due to the } \\
\text { operation of this programme }\end{array}$ & $\begin{array}{c}4 \\
(1.4 \%)\end{array}$ & $\begin{array}{c}65 \\
(23.2 \%)\end{array}$ & $\begin{array}{c}27 \\
(9.6 \%)\end{array}$ & $\begin{array}{c}136 \\
(48.4 \%)\end{array}$ & $\begin{array}{c}49 \\
(17.4 \%)\end{array}$ & 3.57 & 1.070 \\
\hline $\begin{array}{l}\text { 2.There is improvement in simple arithmetic calculations skills of the pupils } \\
\text { due to the operation of this programme }\end{array}$ & $\begin{array}{c}4 \\
(1.4 \%)\end{array}$ & $\begin{array}{c}63 \\
(22.4 \%)\end{array}$ & $\begin{array}{c}32 \\
(11.4 \%)\end{array}$ & $\begin{array}{c}117 \\
(41.6 \%)\end{array}$ & $\begin{array}{c}65 \\
(23.2 \%)\end{array}$ & 3.63 & 1.111 \\
\hline $\begin{array}{l}\text { 3.Learners improved in recognition of alphabet letters due to the operation of } \\
\text { this programme }\end{array}$ & $\begin{array}{c}4 \\
(1.4 \%)\end{array}$ & $\begin{array}{c}57 \\
(20.3 \%)\end{array}$ & $\begin{array}{c}40 \\
(14.2 \%)\end{array}$ & $\begin{array}{c}126 \\
(44.8 \%)\end{array}$ & $\begin{array}{c}54 \\
(19.3 \%)\end{array}$ & 3.60 & 1.058 \\
\hline 4.Programme beneficiaries are satisfied with the benefits & $\begin{array}{c}2 \\
(0.7 \%) \\
\end{array}$ & $\begin{array}{c}59 \\
(21.0 \%) \\
\end{array}$ & $\begin{array}{c}44 \\
(15.7 \%) \\
\end{array}$ & $\begin{array}{c}104 \\
(37.0 \%) \\
\end{array}$ & $\begin{array}{c}72 \\
(25.6 \%) \\
\end{array}$ & 3.66 & 1.097 \\
\hline $\begin{array}{l}\text { 5.Listening learning skills was enhanced through the operation of the } \\
\text { programme }\end{array}$ & $\begin{array}{c}7 \\
(2.5 \%)\end{array}$ & $\begin{array}{c}48 \\
(17.1 \%)\end{array}$ & $\begin{array}{c}58 \\
(20.6 \%) \\
\end{array}$ & $\begin{array}{c}161 \\
(57.3 \%)\end{array}$ & $\begin{array}{c}7 \\
(2.5 \%) \\
\end{array}$ & 3.40 & 0.88 \\
\hline $\begin{array}{l}\text { 6.Speaking learning skills was enhanced through the operation of the } \\
\text { programme }\end{array}$ & $\begin{array}{c}2 \\
(0.7 \%)\end{array}$ & $\begin{array}{c}53 \\
(18.5 \%) \\
\end{array}$ & $\begin{array}{c}52 \\
(18.5 \%) \\
\end{array}$ & $\begin{array}{c}168 \\
(59.8 \%)\end{array}$ & $\begin{array}{c}6 \\
(2.1 \%) \\
\end{array}$ & 3.44 & 0.843 \\
\hline $\begin{array}{l}\text { 7. Writing learning skills was enhanced through the operation of the } \\
\text { programme }\end{array}$ & $\begin{array}{c}4 \\
(1.4 \%) \\
\end{array}$ & $\begin{array}{c}51 \\
(18.1 \%) \\
\end{array}$ & $\begin{array}{c}50 \\
(17.8 \%) \\
\end{array}$ & $\begin{array}{c}169 \\
(60.1 \%) \\
\end{array}$ & $\begin{array}{c}7 \\
(2.5 \%) \\
\end{array}$ & 3.44 & 0.865 \\
\hline 8.Transition rate of learners has increased & $\begin{array}{c}15 \\
(5.3 \%)\end{array}$ & $\begin{array}{c}54 \\
(19.2 \%)\end{array}$ & $\begin{array}{c}23 \\
(8.2 \%)\end{array}$ & $\begin{array}{c}47 \\
(16.7 \%)\end{array}$ & $\begin{array}{c}142 \\
(50.5 \%)\end{array}$ & 3.88 & 1.352 \\
\hline 9.The class average performance has improved & $\begin{array}{c}19 \\
(6.8 \%)\end{array}$ & $\begin{array}{c}50 \\
(17.8 \%) \\
\end{array}$ & $\begin{array}{c}20 \\
(7.1 \%)\end{array}$ & $\begin{array}{c}143 \\
(50.9 \%) \\
\end{array}$ & $\begin{array}{c}49 \\
(17.4 \%) \\
\end{array}$ & 3.54 & 1.168 \\
\hline $\begin{array}{l}\text { 10.Acquisition of literacy and numeracy within times was experienced while } \\
\text { undertaking the programme }\end{array}$ & $\begin{array}{c}2 \\
(0.7 \%) \\
\end{array}$ & $\begin{array}{c}52 \\
(18.5 \%) \\
\end{array}$ & $\begin{array}{c}40 \\
(14.2 \%) \\
\end{array}$ & $\begin{array}{c}176 \\
(62.7 \%) \\
\end{array}$ & \begin{tabular}{c|c|}
11 \\
$(3.9 \%)$ \\
\end{tabular} & 3.50 & 0.859 \\
\hline Composite Mean and SD & & & & & & 3.56 & 0.995 \\
\hline
\end{tabular}

As shown in Table 1, the 10 statements were used to generate data on performance of literacy and numeracy educational. The means of these statements were summed up and used to compute the composite mean and standard deviation that resulted to 3.56 and 0.995 respectively. Statements with means below the composite mean were considered to influence the performance negatively whilst statements with means above the composite mean influenced performance positively.

Generally there was great improvement upon the operationalization of the programme and the intervention has significantly helped the learners who were involved in the programme and teachers who were trained on the new methodology. Simple arithmetic calculation skills, alphabetical letter recognition skills, enhancement of reading skills, satisfaction of the beneficiaries, and general performance of all the learners in class improved. Transition level to another level was excellent according to the findings since it was a government requirement that all learners should proceed to the next class. However, there were areas which needed more effort to be applied for example help learners on how to comprehend what they have learned. This also means that if the learners are not able to comprehend what they have read then simple calculation would be a problem. Most learners have slightly improved on speaking skill and could be able to pronounce the letter sounds correctly even without the help of the teacher but a few had a problem on the mix up of the first language and the second language. Writing skills was enhanced through the operation of the programme although needs a lot of practice. Due to the introduction of the new methods and additional of resources for example textbooks and other reading materials have contributed to great improvement of some learners learning skills whereby an average performance was experienced unlike in the previous programme. Acquisition of literacy and numeracy within time did not much influence performance of literacy and numeracy educational programme but it was better than earlier before the intervention programme. The interviews conducted revealed the respondents were in agreement that although the programme had enhanced brought some performance, there was still room and need for more improvement as one Curriculum Support Officers pointed out: "Most learners who were not able to attend school in regular basis can now attend classes without interference since most of them have been provided with text books and writing material by the government and the implementing organization." Curriculum Support Officer, Embakasi Sub-County the interviews also revealed that the teachers were still relying on the old teaching methods as one of the Research Triangle International Monitoring and Evaluation Officer: "Teachers have ignored the usage of new textbooks hence follows the old methodology of self-centered instead of learner centered. Frequent visits to classroom should be embraced so as to encourage the teachers to adapt new teachers guide given by TUSOME which has the new methodologies of teaching these skills." Research Triangle Institute Monitoring and Evaluation Officer The interview with the Curriculum Support Officer collaborated with the quantitative results who indicated that "Listening, speaking and writing skills has been enhanced since many learners have their own text books and can be able to at least do some practice of the work taught in the absences of the teacher." Curriculum Support Officer Langata Sub-County Interview with Research Triangle International Monitoring and Evaluation Officer indicated that class average performance had somehow significantly improved although a lot more needed to be implemented to realize the full potential: "More materials like textbooks for both learners and teachers guides which have been distributed to schools have really helped in improving the learning skills but more emphasis should be put into the usage of methodology." Research Triangle Monitoring and Evaluation Officer. 


\subsubsection{Overall descriptive analysis on implementing change and performance of literacy and numeracy educational programme}

Implementing change results is a crucial process which involves analysis, interpretation of data and implementing change found while undertaking the process. This means that every relevant information and experiences gathered from those who are directly affected increases the accountability of the participants who have a direct interest in implementation of the programme. In a bid to arrive at the realization of this process the study examined the extent to which implementing change was achieved and the influence it had on the performance of literacy and numeracy educational programme in public primary schools Nairobi, county Kenya. The views of the respondents on implementing change were assessed and measured using a 5point likert-scale whereby: Strongly disagree $(\mathrm{SD})=1$, Disagree $(D)=2$, Neutral $(N)=3$, Agree $(A)=4$ and Strongly Agree $(\mathrm{SA})=5$. Line mean score and standard deviation of each of the opinions was compared with the respective composite scores for both interpretation and conclusion purposes. The results are presented in Table 1.

Table 2: Implementing Change and Performance of Literacy and Numeracy Educational Programme

\begin{tabular}{|c|c|c|c|c|c|c|c|}
\hline Implementing change (statements) & $\begin{array}{l}\mathrm{SD} \\
\mathrm{F} \\
(\%)\end{array}$ & $\begin{array}{l}\mathrm{D} \\
\mathrm{F} \\
(\%)\end{array}$ & $\begin{array}{l}\mathrm{N} \\
\mathrm{F} \\
(\%)\end{array}$ & $\begin{array}{c}\mathrm{A} \\
\mathrm{F} \\
(\%)\end{array}$ & $\begin{array}{l}\text { SA } \\
\text { F } \\
(\%)\end{array}$ & Mean & $\begin{array}{c}\text { Std. } \\
\text { Deviation }\end{array}$ \\
\hline \multicolumn{8}{|l|}{ Reviewing collected data } \\
\hline $\begin{array}{l}\text { 1.All stakeholders counter checked the number of TARGERINE } \\
\text { transmitted reports for correction and reliability }\end{array}$ & $\begin{array}{c}6 \\
(2.1 \%) \\
\end{array}$ & \begin{tabular}{c|}
31 \\
$(11.0 \%)$ \\
\end{tabular} & \begin{tabular}{c|c|}
91 \\
$(32.4 \%)$
\end{tabular} & $\begin{array}{c}62 \\
(22.1 \%)\end{array}$ & \begin{tabular}{c|c|}
91 \\
$(32.4 \%)$
\end{tabular} & 3.72 & 1.097 \\
\hline $\begin{array}{l}\text { 2.TARGERINE tool facilitated for accurate and adequate information for } \\
\text { the program }\end{array}$ & $\begin{array}{c}7 \\
(2.5 \%)\end{array}$ & $\begin{array}{c}30 \\
(10.6 \%)\end{array}$ & \begin{tabular}{c|c|}
89 \\
$(31.7 \%)$
\end{tabular} & $\begin{array}{c}68 \\
(24.2 \%)\end{array}$ & \begin{tabular}{c|c|}
87 \\
$(31.0 \%)$
\end{tabular} & 3.70 & 1.093 \\
\hline $\begin{array}{l}\text { 3.TARGERINE tool helped improve the implementation of the project } \\
\text { activities such as collection of data during class observation }\end{array}$ & $\begin{array}{c}17 \\
(6.1 \%) \\
\end{array}$ & \begin{tabular}{c|c|}
20 \\
$(7.1 \%)$ \\
\end{tabular} & \begin{tabular}{c|c|}
82 \\
$(29.2 \%)$ \\
\end{tabular} & \begin{tabular}{c|c|}
74 \\
$(26.3 \%)$ \\
\end{tabular} & \begin{tabular}{c|c|}
88 \\
$(31.3 \%)$ \\
\end{tabular} & 3.70 & 1.161 \\
\hline $\begin{array}{l}\text { 4.The information collected improved the process of involving the } \\
\text { stakeholders in transmitting reliable reports }\end{array}$ & $\begin{array}{c}15 \\
(5.3 \%) \\
\end{array}$ & $\begin{array}{c}32 \\
(11.4 \%)\end{array}$ & $\begin{array}{c}50 \\
(17.8 \%) \\
\end{array}$ & \begin{tabular}{|c|}
82 \\
$(29.2 \%)$ \\
\end{tabular} & \begin{tabular}{c|c|}
102 \\
$(36.3 \%)$
\end{tabular} & 3.80 & 1.200 \\
\hline $\begin{array}{l}\text { 5.Stakeholders reviewed data collected and made changes to the } \\
\text { identified gaps in the reports }\end{array}$ & $\begin{array}{c}15 \\
(5.3 \%)\end{array}$ & $\begin{array}{c}22 \\
(7.8 \%) \\
\end{array}$ & \begin{tabular}{c|}
60 \\
$(21.4 \%)$ \\
\end{tabular} & \begin{tabular}{|c|}
94 \\
$(33.5 \%)$ \\
\end{tabular} & \begin{tabular}{c|c|}
90 \\
$(32.0 \%)$
\end{tabular} & 3.79 & 1.135 \\
\hline \multicolumn{8}{|l|}{ Number of transmitted reports } \\
\hline \begin{tabular}{|l|} 
6.Data collected from the \\
TARGERINE report was reviewed and analyzed
\end{tabular} & $\begin{array}{c}6 \\
(2.1 \%) \\
\end{array}$ & \begin{tabular}{|c|}
33 \\
$(11.7 \%)$ \\
\end{tabular} & \begin{tabular}{|c|}
89 \\
$(31.7 \%)$ \\
\end{tabular} & \begin{tabular}{|c|}
87 \\
$(31.0 \%)$ \\
\end{tabular} & \begin{tabular}{c|c|}
66 \\
$(23.5 \%)$ \\
\end{tabular} & 3.62 & 1.036 \\
\hline $\begin{array}{l}\text { 7.The number of transmitted report lead to improved results and the } \\
\text { quality of project intervention in literacy and numeracy educational } \\
\text { lessons }\end{array}$ & $\begin{array}{c}9 \\
(3.2 \%)\end{array}$ & $\begin{array}{c}30 \\
(10.7 \%)\end{array}$ & $\begin{array}{c}90 \\
(32.0 \%)\end{array}$ & $\begin{array}{c}65 \\
(23.1 \%)\end{array}$ & $\begin{array}{c}87 \\
(31.0 \%)\end{array}$ & 3.68 & 1.117 \\
\hline $\begin{array}{l}\text { 8.Shared transmitted reports led to identifying areas with large number of } \\
\text { participants and with less participants }\end{array}$ & $\begin{array}{c}19 \\
(6.8 \%) \\
\end{array}$ & $\begin{array}{c}20 \\
(7.1 \%) \\
\end{array}$ & \begin{tabular}{c|c|}
50 \\
$(17.8 \%)$ \\
\end{tabular} & \begin{tabular}{|c|}
85 \\
$(30.2 \%)$ \\
\end{tabular} & \begin{tabular}{c|c|}
107 \\
$(38.1 \%)$
\end{tabular} & 3.86 & 1.199 \\
\hline $\begin{array}{l}\text { 9.Transmitted report improved the allocation of resources for example the } \\
\text { areas which needed more personnel's for supervising literacy and } \\
\text { numeracy programme }\end{array}$ & $\begin{array}{c}31 \\
(11.0 \%)\end{array}$ & $\begin{array}{c}8 \\
(2.8 \%)\end{array}$ & $\begin{array}{c}45 \\
(16.0 \%)\end{array}$ & $\begin{array}{c}90 \\
(32.0 \%)\end{array}$ & $\left(\begin{array}{c}107 \\
(38.1 \%)\end{array}\right.$ & 3.83 & 1.275 \\
\hline \multicolumn{8}{|l|}{ Utilization of $M \& E$ results } \\
\hline $\begin{array}{l}\text { 10.M\&E results were used to improve projects activities such as } \\
\text { allocation of resources }\end{array}$ & $\begin{array}{c}7 \\
(2.5 \%) \\
\end{array}$ & $\begin{array}{c}35 \\
(12.5 \%) \\
\end{array}$ & $\begin{array}{c}89 \\
(31.7 \%) \\
\end{array}$ & \begin{tabular}{|c|}
52 \\
$(18.5 \%)$ \\
\end{tabular} & \begin{tabular}{c|c|}
98 \\
$(34.8 \%)$
\end{tabular} & 3.71 & 1.143 \\
\hline $\begin{array}{l}\text { 11.The M\&E results obtained from the programme excises were } \\
\text { disseminated for utilization by all the stakeholders in order to better the } \\
\text { results of literacy and numeracy educational program }\end{array}$ & $\begin{array}{c}11 \\
(3.9 \%)\end{array}$ & $\begin{array}{c}33 \\
(11.7 \%)\end{array}$ & $\begin{array}{c}80 \\
(28.5 \%)\end{array}$ & $\begin{array}{c}60 \\
(21.4 \%)\end{array}$ & $\begin{array}{c}97 \\
(34.5 \%)\end{array}$ & 3.71 & 1.171 \\
\hline $\begin{array}{l}\text { 12.M\&E results improved the quality of program intervention such as } \\
\text { literacy and numeracy }\end{array}$ & $\begin{array}{c}10 \\
(3.6 \%)\end{array}$ & $\begin{array}{c}43 \\
(15.3 \%) \\
\end{array}$ & \begin{tabular}{|c|}
71 \\
$(25.3 \%)$ \\
\end{tabular} & \begin{tabular}{c|c|}
49 \\
$(17.4 \%)$ \\
\end{tabular} & \begin{tabular}{c|}
108 \\
$(38.4 \%)$
\end{tabular} & 3.72 & 1.223 \\
\hline 13.M\&E results improved the use of financial and resource allocation & \begin{tabular}{|c|}
13 \\
$(4.6 \%)$ \\
\end{tabular} & $\begin{array}{c}46 \\
(16.4 \%) \\
\end{array}$ & \begin{tabular}{c|c|}
64 \\
$(22.8 \%)$
\end{tabular} & \begin{tabular}{c|c|}
48 \\
$(17.1 \%)$ \\
\end{tabular} & $\begin{array}{c}110 \\
(39.1 \%) \\
\end{array}$ & 3.70 & 1.267 \\
\hline $\begin{array}{l}\text { 14.M\&E results improved the designs and performance of literacy and } \\
\text { numeracy educational programme }\end{array}$ & \begin{tabular}{|c|}
13 \\
$(4.6 \%)$ \\
\end{tabular} & $\begin{array}{c}40 \\
(14.2 \%) \\
\end{array}$ & \begin{tabular}{|c|}
70 \\
$(24.9 \%)$ \\
\end{tabular} & $\begin{array}{c}46 \\
(16.4 \%) \\
\end{array}$ & \begin{tabular}{c|c|}
112 \\
$(39.9 \%)$
\end{tabular} & 3.73 & 1.251 \\
\hline \multicolumn{8}{|l|}{ Project intervention } \\
\hline $\begin{array}{l}\text { 15.The intended participants for the intervention were carefully identified } \\
\text { and possible settings to each participants in the programme was done }\end{array}$ & $\begin{array}{c}23 \\
(8.2 \%) \\
\end{array}$ & $\begin{array}{c}30 \\
(10.7 \%) \\
\end{array}$ & $\begin{array}{c}60 \\
(21.4 \%)\end{array}$ & $\begin{array}{c}56 \\
(19.9 \%) \\
\end{array}$ & $\begin{array}{c}112 \\
(39.8 \%)\end{array}$ & 3.73 & 1.306 \\
\hline $\begin{array}{l}\text { 16. M\&E activities for intervention were developed and materials } \\
\text { gathered appropriately }\end{array}$ & $\begin{array}{c}28 \\
(10.0 \%) \\
\end{array}$ & \begin{tabular}{c|c|}
25 \\
$(8.9 \%)$ \\
\end{tabular} & $\begin{array}{c}46 \\
(16.3 \%) \\
\end{array}$ & $\begin{array}{c}77 \\
(27.4 \%) \\
\end{array}$ & \begin{tabular}{c|c}
105 \\
$(37.4 \%)$
\end{tabular} & 3.73 & 1.313 \\
\hline 17.M\&E resources for intervention were clearly specified and located & $\begin{array}{c}20 \\
(7.1 \%)\end{array}$ & $\begin{array}{c}33 \\
(11.7 \%) \\
\end{array}$ & \begin{tabular}{|c|}
39 \\
$(13.9 \%)$ \\
\end{tabular} & $\begin{array}{c}77 \\
(27.4 \%) \\
\end{array}$ & \begin{tabular}{|c|}
112 \\
$(39.9 \%)$ \\
\end{tabular} & 3.81 & 1.272 \\
\hline $\begin{array}{l}\text { 18.Progress for intervention activities were well monitored and evaluated } \\
\text { for the success of the program }\end{array}$ & $\begin{array}{c}19 \\
(6.8 \%) \\
\end{array}$ & $\begin{array}{c}30 \\
(10.7 \%) \\
\end{array}$ & \begin{tabular}{c|c|}
43 \\
$(15.3 \%)$ \\
\end{tabular} & $\begin{array}{c}70 \\
(24.9 \%) \\
\end{array}$ & \begin{tabular}{|c|}
119 \\
$(42.3 \%)$ \\
\end{tabular} & 3.85 & 1.264 \\
\hline Composite Mean and SD & & & & & & 3.74 & 1.198 \\
\hline
\end{tabular}

The means of 17 items used to generate data on implementing change for Monitoring and Evaluationwere summed up and used to compute the composite mean and standard deviation that resulted to 3.74 and 1.198 respectively (Table 2). The statements with lower mean compared to the composite mean were deemed positive and thus influenced performance of the programme negatively.

In Table 2, the first statement line item mean score was 3.72 and standard deviation of 1.198 which was slightly below the composite mean 3.74 and standard deviation of 1.198 
implying that somehow counter checking of TARGERINE reports to allow corrections and reliability before transmission did not have much difference on participation of all stakeholders. This means it positively influenced the performance of literacy and numeracy educational programme. A standard deviation of 1.097 was below the composite a 3.74 and standard deviation of 1.198 show that opinions converged.

The second statement had a line item mean score of 3.70 and standard deviation of 1.093 which was below the composite mean of 3.74 and standard deviation of 1.198 implying that the accuracy and adequacy of information was not facilitated by the TANGERINE tool. This would mean that TANGERINE as a tool is not sufficiently utilized and therefore need for follow up to ensure all the stakeholders get to understand the importance of such a tool in implementation of the literacy and numeracy programme. A standard deviation of 1.093 against 1.198 indicated that respondents' opinions were more consistent with one another.

Third statement had a line item mean score of 3.70 and standard deviation of 1.161 which was realized and fell below the composite mean of 3.74 and standard deviation of 1.198. This means that TANGERINE tool did not help in improving the implementation of the project activities such as collection of data during the classroom observation meaning that it had a negative influence on the performance of literacy and numeracy educational programme. A lower standard deviation of 1.161 against the composite 1.198 was an indication that the views converged.

Fourth, statement had a line item mean score of 3.80 and standard deviation of 1.200 which was higher than 3.74 and standard deviation of 1.198 . The results means that the line item influences the performance of literacy and numeracy educational programme positively. A standard deviation of 1.200 was lower than the composite 1.198 hence opinions were inconsistent.

Fifth statement had a mean score 3.79 and standard deviation of 1.135 with composite mean of 3.74 and standard deviation of 1.198 implying that data collected was reviewed by the stakeholders and changes made to gaps identified in the reports. This had positive influence of performance of literacy and numeracy of educational programme. It is also important to accord the stakeholder a second chance to review the reports to ensure the information being disseminated is more reliable for use across board. A standard deviation of 1.135 below the composite 1.198 implied that opinions converged.

Sixth, statement had mean score of 3.62 and standard deviation of 1.036 was obtained which was lower than the composite mean of 3.74 and standard deviation of 1.198 , implying that reviewing and analysis done was not appropriate and this could be as a result of either weak skills or lack of proper facilitations during workshops and seminar trainings. These two aspects must be checked and corrected to ensure smooth implementation of the programme. A lower standard deviation of 1.036 against 1.198 confirmed that opinions converged.
Seventh, statement had a mean score of 3.68 and standard deviation of 1.117 . This was below the composite mean of 3.74 standard deviation of 1.198 implying that number of transmitted reports did not lead to improvement of results and quality of project intervention in literacy and numeracy educational programme. This could mean the quality of reports might have been compromised or reports were not delivered in time to deduce the best practices and make changes where necessary hence the need to observe some of these procedures in the future for good performance of the programme. A lower standard deviation of 1.117 indicated that opinions were consistent to this statement.

Eighth, statement had a higher mean which was subsequently obtained 3.86 and standard deviation of 1.199 which was greater than the composite implying that the number of participants, either large or small (small), were identified through the transmitted reports meaning that it influenced performance of literacy and numeracy educational programme positively, With standard deviation of 1.199 against 1.198 the composite, the opinions appeared to have diverged.

Ninth, statement obtained a mean score of 3.83 and standard deviation of 1.275 which was higher than the composite mean of 3.74 and standard deviation of 1.198 implying that number of transmitted reports indeed led to improvement of results and the quality of project intervention in the programme. A standard deviation of 1.275 was above the composite hence opinions diverged.

Tenth, statement had a mean score of 3.71 and standard deviation of 1.143 which was lower than the composite mean 3.74 and standard deviation of 1.198 implying that Monitoring and Evaluation results were not used in improving class activities such as resource allocation. It also means that the line item negatively influences performance of literacy and numeracy educational programme therefore need to fully make use of any information gathered through $\mathrm{M} \& \mathrm{E}$ for it is part of programme implementation and it can inform the best and reliable decision making process. A lower standard deviation of 1.143 against 1.198 indicated that opinions lacked consistency.

Eleventh, statement a mean score of 3.71 and standard deviation of $1,143 \mathrm{a}$ composite mean of 3.74 and standard deviation of 1.198 implied that Monitoring and Evaluation results developed from programme activities were not disseminated. It should be noted that missing to disseminate vital Monitoring and Evaluation information developed from the programme implementation exercises can influence the programme negatively. A standard deviation of 1.171 below the composite standard deviation of 1.171 indicated that opinions converged.

Twelfth, statement had a mean score of 3.72 and standard deviation of 1.233 below the composite mean of 3.74 and standard deviation of 1.198 hence programme intervention were not improved by Monitoring and Evaluation results. The line item influences performance of literacy and numeracy educational programme negatively. There is still need, therefore, to train the stakeholders more on the importance of Monitoring and Evaluation results and part of 
implementing the programme to reap extra benefits and enhance performance of literacy and numeracy programme. A higher standard deviation of 1.223 against the composite mean of 1.198 meaning that opinions did not converge on this statement.

Thirteenth statement had a line item mean score of 3.70 and standard deviation of 1.267 which was lower than the composite mean of 3.74 and standard deviation of 1.198 which implies that it influences the performance of literacy and numeracy educational programme negatively and also results of monitoring and evaluation did not improve the quality of programme intervention in literacy and numeracy skills and this could have had a significant negative impact to both the implementers and the beneficiaries. With a higher standard deviation of 1.267 against the composite mean of 1.198, it could be noted that divergence was reported in the opinions.

Fourteenth, statement had a mean score of 3.73 and standard deviation of 1.251 which was below the composite mean of 3.74 and standard deviation of 1.198. The line item influences performance of literacy and numeracy educational programme negatively which implies that Monitoring and Evaluation results did not contribute in improving the designs of the program. It means that Monitoring and Evaluation is still undervalued and there is urgency for its institutionalization in the literacy and numeracy programme. A standard deviation of 1.251 which was above the composite score of 1.198 is indicative that opinions diverged.

Fifteenth statement had a mean score of 3.73 and standard deviation of 1.306 slightly below the composite mean of 3.74 and standard deviation of 1.198. The line item influences performance of literacy and numeracy educational programme negatively implying that the process of arriving at the intended participants for this intervention was wrongly or hurriedly done. Perhaps in the future there would be need to carry out needs assessment to avoid similar anomalies. With a higher standard deviation of 1.306 against 1,198 the opinions definitely did not converge.

Sixteenth, a statement, mean score 3.73 and standard deviation of 1.313 slightly below composite mean of 3.74 and standard deviation of 1.198 which implies that Monitoring and Evaluation activities for intervention were not properly developed and the materials gathered were not appropriate in the implementation of the programme. This begs the question whether stakeholders were genuinely involved and if so, if their full participation was well sought or incorporated, hence need for improvement. A standard deviation of 1.313 was way above the composite and standard deviation of 1.198 indicated that there were inconsistencies opinions from the participants in the study.

On the seventeenth statement, a higher mean score of 3.81 and standard deviation of 1.272 which was higher than composite mean of 3.74 and standard deviation of 1.198 which implies that the programme had been well planned with Monitoring and Evaluation resources. Although resources may be located and even specified for Monitoring and Evaluation work or activities, if the plan is not clearly outlining how these activities ought to be conducted, then it remains a challenge and hence myriad issues may start arising that would directly or indirectly affect implementation of the programme. A higher standard deviation of 1.272 against 1.198 indicative opinions diverged.

The last eighteenth statement had mean score of 3.85 and standard deviation of 1.264 , this would imply that progress for intervention activities was well monitored and evaluated for the success of the program hence a positive influence on the performance of literacy and numeracy educational programme. It was however noted that opinions diverged given a higher standard of 1.264 against the composite of 1.198 on this statement.

Results of interviews with key informants showed that implementing change for Monitoring and Evaluation influenced performance of literacy and numeracy educational programme. The results of the interviews were, therefore, consistent with the quantitative data. The following are key responses obtained from the key informants: "Since implementing the programme, started there was great change and tremendous improvement on literacy and numeracy educational programme though still there a few challenges encountered in the process. Leaners are able to read and calculate simple arithmetic." (Statements from West lands sub-county).

\subsection{Correlation between implemetating change and performance of literacy and numeracy educational programme}

To assess the magnitude of the relationship between implementing change and performance of literacy, and numeracy educational programmea correlation analysis was conducted. Table 3 summarizes the results.

Table 3: Correlation between Implementing Change and Performance of Literacy and Numeracy Educational Programme

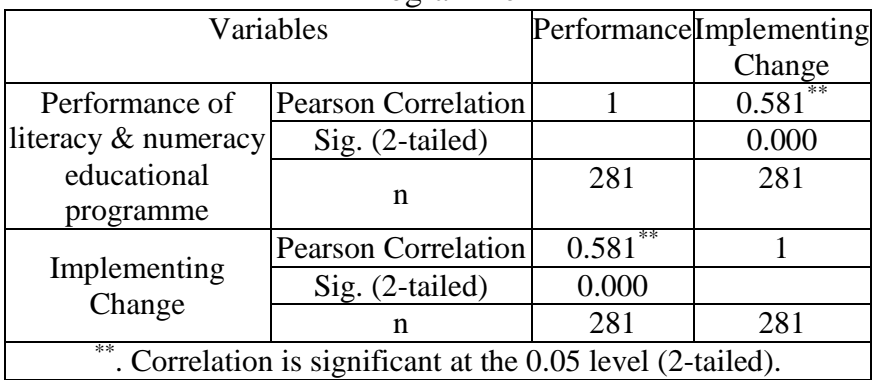

Given a Pearson correlation of 0.581 , a strong positive relationship between implementing change and performance of literacy and numeracy educational programme existed. Thus $(\mathrm{r}=.0 .581, \mathrm{p}<0.05)$. As correlation however does not mean causality; therein a regression analysis was conducted to verify if there is a statistical relationship between implementation change and performanceof literacy and numeracy educational programme.

4.3 Inferential analysis of implemetating change and performance of literacy and numeracy educational programme 
The following hypothesis was tested using linearsimple regression model to satisfy the requirements ofthe objective under study:

$\mathbf{H}_{0}$ : Implementing change has no significant influence on performance of literacy and numeracy educational programs in public primary schools in Nairobi County, Kenya.

$\mathbf{H}_{1:}$ Implementing change has significant influence on performance of literacy and numeracy educational programs in public primary schools in Nairobi County, Kenya

The null hypothesis was tested using the below linear regression model:

$\mathrm{y}=\mathrm{a}+\mathrm{b}_{5} \mathrm{X}_{5}+\mathrm{e}$

Where:

$y$ - Performance of literacy and numeracy educational program

$X_{5}$ - Implementing change

a - Regression constant

$\varepsilon$ - Error term

Table 3: Implementation Change and Performance of Literacy and Numeracy Educational Programme

\begin{tabular}{|c|c|c|c|c|}
\hline \multicolumn{5}{|c|}{ Model Summary } \\
\hline Model & $\mathrm{R}$ & R square & $\begin{array}{l}\text { Adjusted } \\
\text { R Square }\end{array}$ & $\begin{array}{c}\text { Std. Error of } \\
\text { the Estimate }\end{array}$ \\
\hline & $0.581^{\mathrm{a}}$ & 0.337 & 0.335 & 0.70161 \\
\hline \multicolumn{4}{|c}{ a. Predictors: (Constant), Implementing Change } \\
\hline
\end{tabular}

\begin{tabular}{|c|c|c|c|c|c|}
\hline \multicolumn{7}{|c|}{ ANOVA } \\
\hline Model & Sum of squares & Df & Mean Square & F & Sig. \\
\hline Regression & 69.905 & 1 & 69.905 & 142.01 & $0.000^{\mathrm{b}}$ \\
\hline Residual & 137.34 & 279 & 0.492 & & \\
\hline Total & 4347.5 & 280 & & & \\
\hline
\end{tabular}

a. Dependent Variable: Performance of literacy and numeracy educational programme

b. Predictors: (Constant) Implementing Change

\begin{tabular}{|c|c|c|c|c|c|}
\hline \multicolumn{5}{|c|}{ Coefficients } & \\
\hline \multirow{3}{*}{ Model } & $\begin{array}{c}\text { Unstandardized } \\
\text { Coefficients }\end{array}$ & $\begin{array}{c}\text { Standardized } \\
\text { Coefficients }\end{array}$ & \multirow{3}{*}{$\mathrm{t}$} & \multirow{2}{*}{ Sig. } \\
\cline { 2 - 5 } & $\mathrm{B}$ & $\begin{array}{c}\text { Std. } \\
\text { Error }\end{array}$ & Beta & & \\
\hline (Constant) & -0.151 & 0.042 & & -3.576 & 0 \\
\hline Implementing Change & 0.445 & 0.038 & 0.581 & 11.917 & 0 \\
\hline
\end{tabular}

Model: $(\beta=0.445, \mathrm{t}=11.917, \mathrm{p}=0.000<0.05)$

\section{Dependent Variable: performance of literacy and numeracy educational programme}

In Table 4 implementing change has statistically significant influence on performance of literacy and numeracy educational programme $(\beta=0.445, \mathrm{t}=11.917, \mathrm{p}=0.000<0.05)$ implying that stakeholder engagement had a significant influence on performance of literacy and numeracy educational programme

The assessment of the test of coefficient of R-squared is 0.337 and $\mathrm{r}=0.581$. This demonstrates that implementing change has strongly influenced performance of literacy and numeracy educational programme by 0.337 , implying that implementing change explained $33.7 \%$ of variations in the performance of literacy and numeracy educational programme in public primary schools in Nairobi County, Kenya. So there are other factors which could influence the performance of literacy and numeracy educational programme which are explained by the remaining percentage $66.3 \%$

Positive beta coefficient for implementing change is 0.445 suggesting a direct relationship exists as per the model implying there was a positive significant relationship between implementing change and performance of literacy and numeracy educational programme at $5 \%(\mathrm{p}=0.000)$ level of significance.

The overall F-statistic is 142.010 with a p-value of $0.000<0.05$ which implies that there was a statistical relationship between stakeholder engagement and performance of literacy and numeracy educational programme. Based on the research findings, therefore we reject the null hypothesis that states that: $\boldsymbol{H}_{0: \text { Stakeholders }}$ engagement has no significant influence on performance of literacy and numeracy educational programme in public primary schools in Nairobi County, Kenya. The conclusion made in the study meant that implementing change has a significant influence on performance of literacy and numeracy educational programme in public primary schools in Nairobi County, Kenya. Using the statistical findings in table 4 the regression model equation obtained from this output was thus substituted:

$y=-0.151+0.581 X_{1}+e$

Where:

$y$ - Performance of literacy and numeracy educational programme

$X_{l}$ - Stakeholder engagement

Results or findings of implementing change concurred with studies by Nzweke, Olandejo, and Emoh (2015) determined that there was significant relationship between implementing change and performance of literacy and numeracy educational programme. While also Ouko (2013) arrived at similar conclusions, there was improvement in the way things were done in teaching methodology which has brought some improvement. The current study is for the opinion that even though there was improvement in reading and numeracy skills, still a lot needs to be done especially in classroom teaching. Teachers needs to be monitored frequently in order to acquire enough information on how teachers are using the new teachers guide mode of subject delivery since the performance is still low. Implementing change was found to significantly influence performance of literacy and numeracy educational programme.

\section{Conclusion and Recommendations}

The study established that implementing change as part of the participatory Monitoring and Evaluation had an influence on the performance of the literacy and numeracy educational programme. The study findings further showed that the existence of a strong positive linear correlation between implementing change for Monitoring and Evaluation and performance of literacy and numeracy programme. The implication of these results clearly 
indicates that by engaging the stakeholders in implementing change through indicators such as reviewing of data collected, making transmitted reports readily available for sharing, utilization of Monitoring and Evaluation results and finally making stakeholder's part of project intervention would highly enhance performance of literacy and numeracy educational programme.

It is evident that from the statements on quantitative data, the means of the line items were below the composite mean of the whole implementing change variable. This implies that there is need to engage all stakeholders at all stages of implementing change for Monitoring and Evaluation whereby they should fully be involved in the review of data collected, maximize on the number of transmitted reports about the learning of pupils as far as literacy and numeracy is concerned. Similarly, utilization of Monitoring and Evaluation results is fair although it still needs more improvement to ensure performance of literacy and numeracy educational programme are achieved as intended, not forgetting the project intervention aspects such as resource allocation and monitoring of all programme activities. To sum up, implementing change for Monitoring and Evaluationremains very crucial if at all educational programme have to attain the set objectives.

\section{References}

[1] Aremu, A.O. (2000). Impact of home, school and government on primary school pupils' academic performance. Journal of Exceptional Child, 5(1), 106110.

[2] Asikhia, O. A. (2010). Students and Teachers' Perception on the Causes of Poor performance in Ogun state secondary schools (Nigeria) Implication for Counseling for National Development. In the European Journal of Social Sciences 13 (2), 229-242.

[3] Babbie, E.R. (2010). The Practice of Social Research. $\left(25^{\text {th }}\right.$ edition). California: Wadsworth-Cengage Learning.

[4] Blake, S.C. \& Ottoson, J.M. (2009). Knowledge Utilization: Implication for Evaluation. Journal of New Directions for Evaluation, (2009), 21-34. DOI: 10.1002/ev.311

[5] Butt, A., Naaranoja, M. \& Savolainen, J. (2005). (2016). Project Change Stakeholder Communication. International Journal of Project Management, 34(2016), 1579-1595. http://dx.doi.org/10.1016/j.ijproman.2016.08.010

[6] Cooper, D. \& Schindler, P. (2010). Business Research Methods (11th Ed.) New York: McGraw.

[7] Creswell, J. W, \& Plano C, V. L. (2011). Designing and Conducting Mixed Methods Research (2nd ed.).London: Sage Publications Ltd.

[8] Creswell, J. W. (2012). Educational research; planning conducting and evaluating. Qualitative and quantitative research, upper saddle River, N: Prentice Hall.

[9] Daly, D. 2015. The implementation of a literacy intervention 'Station Teaching' in infant classes in Irish Primary Schools. (PhD Thesis, University College Cork).https://cora.ucc.ie/handle/10468/2588

[10]Ercikan, K., Arim, R., Oliveri, M. \& Sandilands, D. (2008). Evaluation of the Literacy Assessment and
Monitoring Programme (LAMP)/UNESCO Insititure for Statistics (UIS). file://C:/Users/Administrator/Downloads/UNESCO_L AMP.pdf

[11] Estrella, M. (2000). Learning from Change: Issues and Experiences in Participatory Monitoring nd Evaluation. London: Intermediate Technology Publications Limited.

[12] Fardel, K.J. \& Brown, S.A. (2010). Information Systems Appraisal and Coping: The Role of Use Perception.Communications of AIS, 26(6), 107-126. DOI: 10.17705/1CAIS.02606

[13] Forster, M.(2009). Literacy and numeracy diagnostic tools an evaluation Australian Council for Educational Research (ACER). https://research.acer.edu.au/monitoring_learning/18/

[14] Karemesi, J. (2010). Universalizing primary education in Kenya, Is it sustainable? Surfing the Web: http://usbec.wordpress.com

[15] Karim, J. A. (2011). Project Management Information Systems (PMIS) factors; An Empirical Study of their Impact on Project Management Decision Making (PMDM) Performance. Research Journal of Economics $\begin{array}{llll}\text { Business } \quad \text { and 22-27. } & \text { ICT }\end{array}$ https://ojs.journals.cz/index.php/RJEBI/article/view/193

[16] Mayama, L. (2012). Effects of proprietor Interests on Quality of Education in private secondary schools in Bungoma South District in Kenya. (Unpublished M.Ed. Thesis, Masinde Muliro University of Science and Technology).

[17] Mege, C.A. (2014). Influence Of School Environmental Factors on Teaching-Learning Process in Public Primary Schools in Lower Nyokal Division,Homa-Bay District, Kenya. https://www.semanticscholar.org/paper/Influence-ofschool-environmental-factors-on-in-inMege/6d669e6442601f6ef3c34c8625080d27855686dc

[18] Ministry of Education Science and Technology (2005). Delivering Quality Equitable and Training to all Kenyans, Kenya Education Sector Support Programme 2005 -

2010.Nairobi.https://planipolis.iiep.unesco.org/sites/pla nipolis/files/ressources/kenya_kessp_final_2005.pdf

[19] Morrell (2014) Empowering young female teachers to create inclusive learning environments for marginalised girls Morrell F, Young P, Navarrete AO, Omarshah TT, \& van Egmond M. (2014). Theatre for a Change. http://www.tfacafrica.com/wp-

content/uploads/2014/07/Morrell-Young-NavarreteOmarshahEgmond.doc.pdf

[20] Mulongo, G. (2013). Effects of active learning teaching methodology on learner participation. A Journal of Education and Practice, 4(4), 157-168. https://pdfs.semanticscholar.org/1cb8/e4667700c76cac5 1b54ae27acf7675119f49.pdf 